\title{
EFFECT OF ADJUVANT MELATONIN WITH CLOIMIPHENE CITRATE ON OVULATORY AND FERTILITY RATES IN PCOS INFERTILE PATIENTS.
}

KEY WORDS: en-clomiphene citrate, melatonin, oxidative stress, antioxidant.

\section{Dr. Meenal Jain* Associate professor, Obgyn Snmc Agra. *Corresponding Author}

\section{Prof. Richa Singh Professor, Obs \& Gyne, SNMC, Agra.}

\section{Dr. Rachna}

\section{Agarwal}

\author{
Associate Professor, Obs \& Gyne, SNMC, Agra.
}

AIM: To study the effect of adjuvant melatonin with clomiphene citrate on ovulution and fertility rates in infertile PCO patients.

MATERIAL AND METHODS: A total of 107 cases participated in the study out of which 7 women were excluded from the study. So the results of 100 women were analyzed. Out of 100 women 50 were of group A i.e. clomiphene supplemented with melatonin group and 50 were in group B which was clomiphene only group with no supplementation. Cases were followed for three cycles and pregnancy rates in both groups were evaluated.

RESULTS: Study demonstrated the potential benefit of melatonin supplementation in naturally conceived cycles where ovulation induction was given by en-clomiphene citrate. The ovulation rates were comparable in both study Vs control group (68\% Vs $66 \%$ ) while there was increase in pregnancy rate in melatonin group (36\% Vs $24 \%)$. However difference between pregnancy rates in both the groups failed to reach statistically significant levels ( $\mathrm{p}$ value 0.4065).

CONCLUSION: The adjuvant role of melatonin with en-clomiphene citrate in cases of Infertile PCO patients is in improving pregnancy rates; which is due to strong anti-oxidant effect of melatonin which in turn reduces oxidative stress thus resulting in good quality oocyte production.

\section{INTRODUCTION}

Clomiphene citrate, a non steroidal triphenylethylene compound, is the first line medicine used for ovulation in anovulatory women worldwide. In spite of high ovulation induction with use of Clomiphene citrate the pregnancy rate is much lower ${ }^{(1)}$ as Clomiphene citrate increases hydrogen peroxide level in ovary causing increased level of 'reactive oxygen species' thereby increasing oxidative stress. Oxidative stress modifies the quality of oocytes and the embryos hence decreasing fertilisation rates and success of fertility treatment. Anti-estrogenic and oxidative side effects of clomiphene are likely to be one of the causes of suboptimal pregnancy rates in spite of good ovulation rates. To counteract various side effect of clomiphene citrate during ovulation induction it is often supplemented with various other compounds which is deemed to play important role in improving pregnancy outcome in women taking clomiphene citrate.

Melatonin (N-acetyl-5-methoxytryptamine) was first isolated in 1958 as a neuro-hormone mainly synthesised and secreted from the pineal gland. Recently, it has been discovered that melatonin has important oxygen-scavenging properties ${ }^{(2)}$. Compared with other oxygen scavengers, melatonin is of particular interest because it has several qualities distinguishing and rendering it superior to classical anti-oxidative agents, as it exerts its anti-oxidative effects through its receptors, MTl and MT2, but also as a direct free radical scavenger ${ }^{(3)}$. It has binding sites within the nucleus, and is amphiphilic, allowing it to cross cell membranes freely ${ }^{(4)}$. But one of its most unique characteristics is that, unlike classical anti-oxidants, melatonin is a suicidal terminal anti-oxidant. It does not promote oxidation under any circumstances and its metabolites are also capable of acting as anti-oxidants in a 'scavenging cascade reaction' without themselves becoming oxidative ${ }^{(5)}$. Thus oral melatonin supplementation along with enclomiphene citrate during ovarian stimulation can improve the outcomes in infertility treatments for dysovulatory infertility (as in case of PCOS) in terms of improved fertilization rates and pregnancy rates.

\section{MATERIAL AND METHODS}

The study was conducted on patients attending Gynaecology O.P.D in Department of Obstetrics and Gynaecology in collaboration with Department of Radiodiagnosis, S.N. Medical College and Hospital, Agra 100 infertile PCOS patients (PCOS diagnosed by revised Rotterdam's criteria) were recruited for the study.

Revised Rotterdam criteria (2003) (any 2 of these 3).

Oligo/Anovulation.

Clinical \& or biochemical signs of hyperandrogenism.

PCO morphology on US examination ( 7,12 follicles of $<10 \mathrm{~mm}$ and / or ovarian volume $>10 \mathrm{ml}$ per ovary.

Randomly cases were divided into two groups:

A.Study group $(n=50)$ : were given En-Clomiphene citrate(50mg) from day 2 to day 6 of the menstrual cycle along with melatonin $(3 \mathrm{mg})$ once a day for one month

B.Control group $(n=50)$ : were given En-clomiphene citrate (50mg) from day 2 to day 6 of the menstrual cycle.

\section{Criteria For Inclusion:}

1. Cases between 18 to 35 years of age with PCOS (according to definel Rotterdam criteria) willing to conceive.

2. No previous exposure to clomiphene or ovulation induction or any fertility treatment in previous three months.

3. Normal semen analysis, normal results on hysterosalpingogram.

4. No systemic endocrinal disorder (e.g. Hyperprolacinemia, hypothyroidism)

\section{Criteria Of Exclusion:}

1. Male causes of infertility, tubal causes of infertility eg tubal blockade, hydrosalpinx etc

2. Other anovulatory causes:- hypothy roidism hyperprolactinemia.

3. Other causes of infertility like current untreated pelvic pathology including sub-mucosal uterine fibroid, pelvic inflammatory disease, uterine malformations, Asherman's syndrome, moderate to severe endometriosis

4. Malignancy, history of chemoradiation in past or other contraindication to use of clomiphene citrate

5. Hypersensitivity to melatonin or its metabolites

6. Concurrent use of medication like fluvoxamine, cimetidine, carbamazipine, quinolones etc

\section{Evaluation:}

Cases in both groups were called regularly for evaluation and 
follow up which included:

1. Monitoring of follicle development in ovary via transvaginal sonography $(5-7.5 \mathrm{~Hz})$ starting from $9^{\text {th }}$ day of the cycle.

2. Subsequent monitoring on alternate days till leading follicle of atleast $18 \mathrm{~mm}$ was observed sonographically. At this time inj. HCG was administered by intramuscular route in doses of 5000 I.U.

3. Cases were now called for two subsequent days for ultrasongraphic examination for demonstration of ovulation, endometrial thickness and endometrial type.

4. Number of patients with positive ovulation on TVS were considered as 'positive primary outcome'

5. This regimen was repeated for up to 3 cycles depending upon the findings.

6. In follow-up period the cases that missed their periods were called and a urinary pregnancy test was done for detection of pregnancy.Cases with positive UPT were followed sonographically till the earliest demonstration of cardiac activity on trans-vaginal sonography. Cases with a viable pregnancy were considered as 'positive secondary outcome'.

\section{Statistical Analysis And Study Design}

The sample size was calculated using the appropriate formula $\mathrm{Z}^{2} \mathrm{PQ} / \mathrm{d}^{2}$. Where $\mathrm{P}$ and $\mathrm{Q}$ taken as 0.5 to get maximum sample size with $10 \%$ permissible error and $10 \%$ non response rate with $85 \%$ confidence interval. The data was entered in MS Excel and analysed using SPSS ver.18. standard statistical technique were applied according to suitability of data.

Significance of difference in outcome variable between groups was tested by Chi-square test and ' $p$ ' value.

\section{RESULTS}

Ours was a prospective comparative randomised trial conducted from August 2016 to September 2018 in Department of Obstetrics and Gynaecology in collaboration with Department of Radiodiagnosis at S.N. Medical College Agra. Total 100 PCO infertile cases were included in the study, 50 cases belonged to group $A$ in which melatonin supplementation was given along with ovulation induction with en-clomiphene citrate and 50 cases were in group B where ovulation induction with en-clomiphene citrate was given with no supplementation. The results were subjected to statistical analysis wherever applicable. Results were reported as mean and standard deviation. Comparisons of means were carried out using the Student's t-test. p-value $<0.05$ was considered significant.

The following inferences were made in our study:

Table 1: Sociodemographic Profile

\begin{tabular}{|c|c|c|c|}
\hline & \begin{tabular}{|l|} 
Group-A \\
(Clomiphene \\
Citrate + \\
Melatonin)
\end{tabular} & \begin{tabular}{|l|} 
Group -B \\
(Clomiphene \\
Citrate)
\end{tabular} & P value \\
\hline \multicolumn{4}{|c|}{ A. Age (in Years) } \\
\hline $18-25$ & 20 & 20 & 0.9530 \\
\hline $26-35$ & 22 & 23 & \\
\hline$>35$ & 8 & 7 & \\
\hline Mean & $27.86 \pm 5.131$ & $27.8 \pm 5.03$ & \\
\hline \multicolumn{4}{|c|}{ B. Domicile } \\
\hline Rural & 22 & 23 & 0.8407 \\
\hline Urban & 28 & 27 & \\
\hline \multicolumn{4}{|c|}{ C. Socio-economic class } \\
\hline Upper & 14 & 18 & 0.8382 \\
\hline Middle & 14 & 10 & \\
\hline Lower & 22 & 22 & \\
\hline
\end{tabular}

As shown in table 1 mean age observed in group $A$ was $27.86 \pm 5.131$ years while that of group $B$ was $27.80 \pm 5.03$ years. $44 \%$ of women in group $A$ and $46 \%$ of women in group B belonged to rural area while $56 \%$ of women in group $A$ and
$54 \%$ of women in group B belonged to urban areas. Further the groups were also divided into upper, middle and lower according to modified B.J. Prasad scale 2017. Maximum number of patients belonged to lower class in both the groups and $p$ value by statistical analysis was not found to be significant.

Table 2: Distribution According To BMI, Duration, Type And Cause Of Infertility

\begin{tabular}{|c|c|c|c|}
\hline & $\begin{array}{l}\text { Group-A } \\
\text { (CC + } \\
\text { Melatonin) } \\
\end{array}$ & $\begin{array}{l}\text { Group -B } \\
\text { (CC) }\end{array}$ & $P$ value \\
\hline \multicolumn{4}{|l|}{ A. BMI (in $\mathrm{Kg} / \mathrm{m}^{2}$ ) } \\
\hline$<18.5$ (Under Weight) & 6 & 4 & \multirow[t]{5}{*}{0.5599} \\
\hline $18.5-24.9$ (Normal) & 20 & 20 & \\
\hline $25-29.9$ (Over Weight) & 20 & 21 & \\
\hline$\geq 30$ (Obese) & 4 & 5 & \\
\hline Mean & $24.688 \pm 3.586$ & $25.098 \pm 3.421$ & \\
\hline \multicolumn{4}{|c|}{ B. Duration of Infertility(Years) } \\
\hline$<2$ & 12 & 11 & \multirow[t]{5}{*}{0.9616} \\
\hline $2.1-4$ & 12 & 14 & \\
\hline $4.1-6$ & 17 & 15 & \\
\hline$>6$ & 9 & 10 & \\
\hline Mean & $4.48 \pm 2.070$ & $4.46 \pm 2.070$ & \\
\hline \multicolumn{4}{|l|}{ C. Type of Infertility } \\
\hline Primary & 29 & 30 & \multirow[t]{2}{*}{0.8389} \\
\hline Secondary & 21 & 20 & \\
\hline
\end{tabular}

As shown in table 2 in group A $12 \%$ of women were under weight, $40 \%$ were normal, other $40 \%$ were overweight and rest $8 \%$ were obese. While in group B $8 \%$ were under weight, $40 \%$ were normal, $42 \%$ were overweight and rest $10 \%$ were obese.

In group $A$, women showed $<2$ years of infertility in $24 \%, 2-4$ years of infertility in other $24 \%$, 4-6 years of infertility in 34\% and $>6$ years of infertility in rest $18 \%$. While in group B, women showed $<2$ years of infertility in $22 \%, 2-4$ years of infertility in $28 \%, 4-6$ years of infertility in $30 \%$ and $>6$ years of infertility in rest $20 \%$ of women

Further, group A showed primary infertility in 58\% and secondary infertility in $42 \%$ of women. While in group B $60 \%$ had primary infertility and $40 \%$ had secondary infertility.

Table 3: Distribution Of Cases According To Overall Ovulation Rate After Three Cycles Of Ovulation Induction

\begin{tabular}{|l|l|l|l|l|}
\hline \multirow{2}{*}{$\begin{array}{l}\text { Ovulation } \\
\text { Rate }\end{array}$} & \multicolumn{2}{|l|}{$\begin{array}{l}\text { Group-A } \\
\text { (CC + Melatonin) }\end{array}$} & \multicolumn{2}{|l|}{$\begin{array}{l}\text { Group -B } \\
\text { (CC) }\end{array}$} \\
\cline { 2 - 5 } & No. & \%age & No. & \%age \\
\hline Present & 34 & 68 & 33 & 66 \\
\hline Absent & 16 & 32 & 17 & 34 \\
\hline Total & $\mathbf{5 0}$ & $\mathbf{1 0 0}$ & $\mathbf{5 0}$ & $\mathbf{1 0 0}$ \\
\hline $\mathbf{X}^{2}$ & $\mathbf{0 . 0 4 5 2 3}$ & & \\
\hline $\mathbf{P}$ & $\mathbf{0 . 8 3 1 6}$ &
\end{tabular}

Table 3 shows ovulation was demonstrated in 34 out of 50 cases in group $A$ and 33 out of 50 cases in group B demonstrated ovulation. Hence, ovulation rates in group $A$ was $68 \%$ and in group B was $66 \%$ which was comparable in both the groups. $p$ value is not significant $(p=0.8316)$.

Thus, primary outcome in form of ovulation in three cycles was demonstrated by $68 \%$ women in group $A$ and $66 \%$ women in group $B$.

Table 4: Viable Pregnancy Rate After Three Cycles Of Ovulation Induction

\begin{tabular}{|l|l|l|l|l|}
\hline \multirow{2}{*}{$\begin{array}{l}\text { Pregnancy } \\
\text { Rate }\end{array}$} & $\begin{array}{l}\text { Group-A } \\
\text { (CC + Melatonin) }\end{array}$ & \multicolumn{2}{|l|}{$\begin{array}{l}\text { Group -B } \\
\text { (CC) }\end{array}$} \\
\cline { 2 - 5 } & No. & \%age & No. & \%age \\
\hline Present & 18 & 36 & 12 & 24 \\
\hline
\end{tabular}




\begin{tabular}{|l|l|l|l|l|}
\hline Total & 50 & 100 & 50 & 100 \\
\hline $\mathbf{P}$ & 0.4065 & & & \\
\hline
\end{tabular}

According to table 4 secondary outcome in form of demonstration of viable pregnancy was seen in 18 patients in group A and 12 patients in group B. Hence viable pregnancy rate in group A was $36 \%$ while that in group B was $24 \%$. Higher pregnancy rates in group $A$ is attributed due to adjuvant effect of melatonin in form of strong antioxidant effect during ovulation induction with en-clomiphene citrate resulting in good quality oocyte production.

Pregnancy rate were however higher in group $A$ as compared to group $B$ but $p$ value failed to reach statistical significant levels $(p=0.4065)$

\section{DISCUSSION}

Overall only a limited number of clinical studies have investigated the use of melatonin to improve pregnancy outcomes in infertile women. These studies have largely investigated the role of melatonin in increasing clinical pregnancy rates in IVF patients.

\section{Table 5: Effect Of Melatonin Supplementation Therapy} During IVF Studies

\begin{tabular}{|c|c|c|c|c|}
\hline Study & Design & \begin{tabular}{|l|} 
Intervention \\
/ control
\end{tabular} & \begin{tabular}{|l|} 
Sample \\
size
\end{tabular} & Outcome \\
\hline $\begin{array}{l}\text { Eryim } \\
\text { az et } \\
\text { al. } \\
2011^{[6]}\end{array}$ & $\begin{array}{l}\text { Unblinded } \\
\text { randomised } \\
\text { control trial }\end{array}$ & $\begin{array}{l}\text { Oral } \\
\text { melatonin } \\
\text { 3mg/day } \\
\text { until HCG inj. } \\
\text { No melatonin }\end{array}$ & 60 & \begin{tabular}{|l|} 
Higher number \\
of oocyte in \\
melatonin \\
group (11.5 vs \\
$6.9)$ \\
Higher Mature \\
oocyte counts \\
( 9 vs $4.4 \%)$ \\
No difference in \\
fertilization or \\
pregnancy \\
rates
\end{tabular} \\
\hline $\begin{array}{l}\text { Batiogl } \\
\text { u et al. } \\
2012^{[7]}\end{array}$ & $\begin{array}{l}\text { Single } \\
\text { blinded } \\
\text { randomised } \\
\text { control trail }\end{array}$ & \begin{tabular}{|l|} 
Oral \\
melatonin \\
3mg/day \\
No melatonin
\end{tabular} & 85 & \begin{tabular}{|l|} 
Higher \\
percentage of \\
mature oocyte \\
in melatonin \\
group (81.9 vs \\
$75.8 \%)$ \\
Higher rates of \\
good quality \\
embryo \\
No difference in \\
blastocyst or \\
good quality \\
blastocyst
\end{tabular} \\
\hline $\begin{array}{l}\text { Kim et } \\
\text { al. } \\
2013^{[8]}\end{array}$ & $\begin{array}{l}\text { randomised } \\
\text { control trail }\end{array}$ & \begin{tabular}{|l|} 
Adding \\
melatonin in \\
oocyte \\
cultural \\
media \\
No melatonin
\end{tabular} & 111 & $\begin{array}{l}\text { Increased } \\
\text { mature oocyte } \\
\text { Increased } \\
\text { implantation }\end{array}$ \\
\hline $\begin{array}{l}\text { Nishih } \\
\text { ara et } \\
\text { al. } \\
2014^{[9]}\end{array}$ & $\begin{array}{l}\text { Uncontrolle } \\
\text { d before } \\
\text { and after } \\
\text { study }\end{array}$ & \begin{tabular}{|l|} 
Oral \\
melatonin \\
3mg/day \\
No melatonin
\end{tabular} & 97 & $\begin{array}{l}\text { Improved } \\
\text { fertilization } \\
\text { with ICSI } \\
\text { Improved } \\
\text { fertilization in } \\
\text { poor } \\
\text { responders } \\
\text { Improved good } \\
\text { quality embryo }\end{array}$ \\
\hline
\end{tabular}

Further in animal based study by Chaube et al. 2014 ${ }^{[10]}$ concluded that Clomiphene Citrate induces generation of ROS and thereby apoptosis in granulosa cells that are responsible for estradiol $17 \beta$ synthesis. The granulosa cell apoptosis also reduces granulosa cells-oocyte communication by disrupting gap junctions. The disruption of gap junction affects the supply of nutrients and maturation enabling factors that are required for the achievement of meiotic competency of preovulatory oocytes. As a result, oocyte becomes more susceptible towards apoptosis that leads to deterioration of oocyte quality after ovulation leading to poor ART outcome. Thus, based on the animal studies, they suggested the use of melatonin along with clomiphene citrate to overcome the discrepancies due to adverse effects caused by clomiphene citrate at the level of ovary during infertility management in human.

In our study, we demonstrated the potential benefit of melatonin supplementation in naturally conceived cycles where ovulation induction was given by en-clomiphene citrate. The ovulation rates were comparable in both study Vs control group (68\% Vs 66\%) while there was increase in pregnancy rate in study group (36\% Vs $24 \%)$. However difference between pregnancy rates in both the groups failed to reach statistically significant levels ( $p$ value 0.4065 ).

\section{CONCLUSION}

Our study demonstrates the adjuvant role of melatonin with en-clomiphene citrate in cases of PCO infertile patients in improving pregnancy rates; which is due to strong antioxidant effect of melatonin which in turn reduces oxidative stress thus resulting in good quality oocyte production.

Thus melatonin being a novel and cost effective antioxidant can be used for improving fertility outcomes in naturally conceived cycles with clomiphene citrate before proceeding to costlier alternatives like gonadotropins and in vitro fertilization technique. However, since ours is a small scale study, larger randomised control trials are recommended to draw accurate and acceptable conclusions.

\section{REFERENCES}

1. Hughes E, Brown J, Collins JJ, Vanderkerchove P. Clomiphene citrate for unexplained subfertility in women. Cochrane Database Syst Rev. 2010;(1):CD00005

2. Wood S, Quinn A, Troupe S, Kingsland C, Lewis-Jones I. Seasonal variation in assisted conception cycles and the influence of photoperiodism on outcome in in-vitro fertilisation cycles. Hum Fertil.2006;9:223-229.

3. Tamura H, Takasaki A, Taketani T, Tanabe M, Kizuka F, Lee L, et al. The role of melatonin as an antioxidant in the follicle.J Ovarian Res. 2012 Jan 26;5:5.

4. Benítez-King G, Huerto-Delgadillo L, Antón-Tay F. Binding of 3H-melatonin to calmodulin.Life Sci.1993;53:201-207.

5. Ressmeyer A,Mayo J,ZeloskoV,Sáinz R,Tan D, Poeggeler B, Antolín I,Zsizsik B, Reiter R, Hardeland R. Antioxidant properties of the melatonin metabolite N1acetyl-5-methoxykynuramine (AMK): scavenging of free radicals and prevention of protein destruction. Redox Rep. 2003;8:205-213.

6. O. G. Eryilmaz, A. Devran, E. Sarikaya, F. N. Aksakal, L. Mollamahmutoglu, and N. Cicek, "Melatonin improves the oocyte and the embryo in IVF patients with sleep disturbances, but does not improve the sleeping problems," Journal of Assisted Reproduction and Genetics, vol.28, no.9,pp.815-820,2011.

7. A. S. Batioglu, U. U. Sahin, N. Ozturk, and E. Unsal, "The efficacy of melatonin administration on oocyte quality," Gynecological Endocrinology, vol. 28, pp.91-93,2012.

8. M.K.Kim, E.A.Park, H.J.Kimetal., "Does supplementation of in-vitro culture medium with melatonin improve IVF outcome in PCOS?" Reproductive BioMedicine Online, vol.26, no.1,pp. 22-29,2013.

9. T. Nishihara, S. Hashimoto, K. Ito et al., "Oral melatonin supplementation improves oocyte and embryo quality in women undergoing in vitro fertilization-embryo transfer," Gynecological Endocrinology, vol.30, no.5, pp.359-362,2014.

10. Chaube SK, Shrivastav TG, Prasad S, Tiwari M, Tripathi A, Pandey AN, Premkumar KV. Clomiphene citrate induces ROS-mediated apoptosis in mammalian oocytes. Open Journal of Apoptosis. 2014 Jul 28;3(03):52. 